\title{
Aortic Prosthesis-Associated MDR Pseudomonas Infections as a Diagnostic and Therapeutic Challenge
}

\author{
Rita Filipe ${ }^{1,2, *} \mathbb{B}$, Filipa Ceia ${ }^{1,2}$, Ana Cláudia Carvalho ${ }^{1}$, Margarida Tavares ${ }^{1,3}$, José Teixeira ${ }^{4}$ \\ and António Sarmento ${ }^{1,2}$ \\ 1 Infectious Diseases Department, São João University Hospital Center, 4000-319 Porto, Portugal; \\ filipa.ceia@chsj.min-saude.pt (F.C.); aclaudia.carvalho@chsj.min-saude.pt (A.C.C.); \\ margarida.tavares@chsj.min-saude.pt (M.T.); antonio.sarmento@chsj.min-saude.pt (A.S.) \\ 2 Faculty of Medicine, University of Porto, 4000-319 Porto, Portugal \\ 3 EPI Unit, Public Health Institute of Porto University, 4000-319 Porto, Portugal \\ 4 Vascular Surgery Department, São João University Hospital Center, 4000-319 Porto, Portugal; \\ jteixeira@chsj.min-saude.pt \\ * Correspondence: rita.filipe02@chsj.min-saude.pt; Tel.: +351-918-062-838
}

Received: 28 June 2020; Accepted: 8 October 2020; Published: 2 November 2020

\begin{abstract}
Endovascular prostheses are used to treat life-threatening conditions such as ruptured aortic aneurysms. Prosthetic infection cause significant morbidity and mortality, posing important diagnostic and therapeutic challenges. It is particularly difficult to diagnose and, in the era of multidrug resistance (MDR), these type of infections may become even more difficult to treat. Herein, we reported a case of a secondary prosthetic endovascular infection following repeated bacteremia episodes from a urinary source. This case illustrates an MDR Pseudomonas aeruginosa aortic infection that was difficult to diagnose with no oral antibiotic treatment options.
\end{abstract}

Keywords: aortic prosthesis infection; MDR Pseudomonas; PET scan; axilobifemoral revascularization

\section{Case Report}

In 2015, a 59-year-old man underwent emergency surgery to repair a ruptured abdominal aortic aneurysm. An aortobifemoral bypass was performed. As a post-operatory complication, the patient developed a left retroperitoneal hematoma and secondary hydronephrosis, which was managed with a J-J catheter placement. In the following year, he had several episodes of catheter-associated pyelonephritis with repeated isolation of multidrug resistance (MDR), Pseudomonas aeruginosa in urine, and, on one occasion, blood cultures. P. aeruginosa was resistant to ciprofloxacin (minimum inhibitory concentration (MIC) $4 \mu \mathrm{g} / \mathrm{mL}$ ), gentamicin (MIC $8 \mu \mathrm{g} / \mathrm{mL}$ ), and imipenem (MIC $16 \mu \mathrm{g} / \mathrm{mL}$ ); sensitive to amikacin, ceftazidime, tobramycin, cefepime, and colistin; and it showed intermediate resistance to aztreonam. MIC were extrapolated data from VITEK ${ }^{\circledR} 2$.

On December 2016, he was admitted in our Department of Infectious Diseases, which has 27 beds and is located at São João Hospital, a tertiary care public university hospital in Oporto, Portugal, with 1100 beds and about 45,500 admissions per year. At that time, he was admitted with another episode of pyelonephritis and J-J catheters were removed. The patient was treated with IV targeted therapy for 14 days (amikacin $1 \mathrm{~g}$ daily and ceftazidime $2 \mathrm{~g}$ every $8 \mathrm{~h}$ ) with clinical and analytical improvement.

Following repeated episodes of infections with the same microorganism, we suspected an infection of the aortobifemoral bypass. An echocardiogram was normal and a full body LeukoScan ${ }^{\circledR}$ did not detect radiolabeled antibodies. Follow-up blood cultures were also negative.

Four days after discharge, the patient was readmitted with fever and peripheral embolization in the inferior limbs. Amikacin and ceftazidime were started. MDR P. aeruginosa was again isolated in 
urine and blood cultures. Pseudomonas was resistant to ciprofloxacin (MIC $4 \mu \mathrm{g} / \mathrm{mL}$ ), gentamicin (MIC $8 \mu \mathrm{g} / \mathrm{mL}$ ), imipenem (MIC $16 \mu \mathrm{g} / \mathrm{mL}$ ), and piperacillin-tazobactam (MIC $128 \mu \mathrm{g} / \mathrm{mL}$ ); sensitive to amikacin, ceftazidime, cefepime, tobramycin, and colistin; and with intermediate resistance to aztreonam. Angio-computerized tomography (CT) showed that there was a fluid collection adjacent to the left psoas muscle with contrast uptake in the collection walls, apparently in continuity of the bypass bifurcation region. This had previously been detected in a post-operatory exam with similar dimensions, suggesting postoperative hematoma. However, given the high suspicion of bypass infection, a LeukoScan ${ }^{\circledR}$ was repeated but again showed no changes. A PET scan was then requested and showed increased 18F-fluorodeoxyglucose (FDG) along the aortic prosthesis to the common iliac artery and external iliac artery, with superior intensity at the distal portion of the aorta and extending to the left psoas muscle suggesting an infectious process (Figure 1).

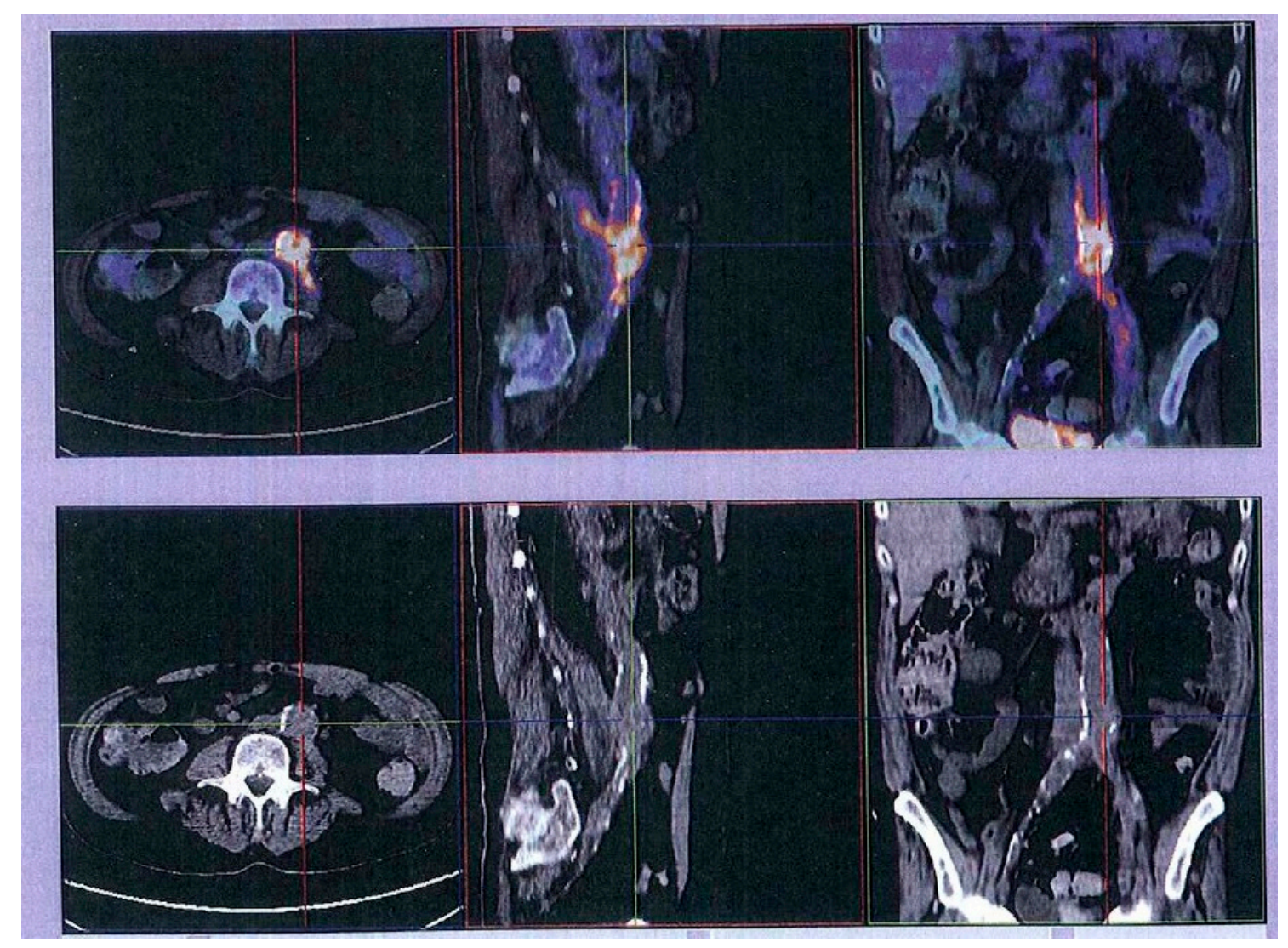

Figure 1. 18F-FDG PET/CT revealing hypercaptation along aortic prosthesis extending into common and left external iliac arteries.

Suppressive antibiotic treatment was considered given the high morbidity and mortality associated to prosthesis removal but due to Pseudomonas, there were no possible oral antibiotics. After consulting the vascular surgeon, the patient underwent aorta-bifemoral bypass removal and extra anatomic revascularization, with a silver impregnated axilobifemoral graft. Aortic graft was placed in thioglycolate broth for $48 \mathrm{~h}$ which was then transferred into a blood agar plate. Culture from the graft confirmed the infection with an isolate of P. aeruginosa, with the same phenotypical profile.

The patient was discharged after completing 10 weeks of antibiotic therapy and remained free of infection for the next 18 months of follow-up.

Of note, in October 2018, he developed a catheter-associated urinary tract infection caused $P$. aeruginosa with the same antimicrobial susceptibility profile, treated successfully with ceftazidime for two weeks. There were no infectious complications in the following year. The patient was also 
admitted into the Vascular Surgery Department for three episodes of bypass occlusion for the last two years that were treated with thrombolytic agents.

\section{Discussion}

Aortic graft infections (AGIs) are defined as infections of any vascular and endovascular grafts implanted from subdiaphragmatic aorta to the groin [1].

The reported rate of AGI is below $1 \%$ in most series, and it is significantly associated with hematogenous spread and surgical site infection [2,3]. However, the incidence is higher when considering only patients treated in the emergency setting and when there is an open surgery $[1,2]$. In fact, in some reports, AGIs range from $0.6-3 \%$ [1].

There are multiple recognized risk factors for endograft infections: prolonged operative time, perioperative antiseptic technique defects, nasal carriage of Staphylococcus aureus, perioperative infection in another site, older age, and chronic diseases. The most important cause of endograft infections is surgical site infection [1].

Besides typical symptoms of systemic infections, diagnosis relies on microbiological diagnosis and imaging findings. However, up to a third of patients with endograft aortic prosthetic infections may present negative blood cultures or negative cultures of the graft/drainage material, thus not having a microbiological diagnosis [2]. When microbiological identification is possible, coagulase-negative Staphylococcus is the most common agent, followed by Pseudomonas aeruginosa, Enterococcus spp. and Staphylococcus aureus [4]. This reflects the most common sources of contamination: skin and adjacent bowel.

Multi-drug resistant (MDR) organisms are an increasing concern and when heterologous material is involved, biofilm may hinder blood sterilization and impair clinical response. It is known that biofilm formation, a complex bacteria network protected in a matrix, can develop in device associated infections and contribute to the survival of bacteria. Bacterial adherence depends on several factors such as the length of stent graft in contact with the arterial wall and on the extent of endothelialization of the stent graft surface by mature collagen tissue [5].

Angio-CT is considered the gold standard for endograft infections because of its high sensitivity (approaching 100\% in most cases, but which decreases to 55\% in late or low-grade infections) and specificity $(100 \%)[1,5]$. Positron emission tomography (PET)-CT and leukocyte scan may be useful to establish the diagnosis [5]. Of note, LeukoScan ${ }^{\circledR}$ is often falsely negative in long standing infections and in patients with repeated courses of antibiotics, as in our case. In our patient, PET was decisive to diagnosis. A study that included 76 patients and a total of 96 prosthetic grafts concluded that PET-CT gave reliable results with an accuracy $>95 \%$ [6].

Because of its low incidence, management of aortic endograft infections is not straightforward and should be evaluated individually. Possible options include endovascular aortic repair, which may impel graft removal, open surgery, or conservative treatment. The latter consists of long term oral suppressive treatment and this is usually considered in high risk patients unfit for surgery, in which, ideally, antibiotic therapy should be directed to an isolated microorganism [7]. Additionally, when there are no oral antimicrobial options, nor parenteral regimens suitable for a parenteral outpatient administration, lifelong treatment may not be practicable. The duration of antibiotic treatment is not widely agreed with.

Mortality associated with endograft infections is variable and ranges from $30-60 \%$, being typically higher in patients treated conservatively [1]. Thus, consensus is that infected material should always be removed, if feasible. Surgical treatment consists of graft removal and revascularization.

In the particular case of Pseudomonas graft infection, many authors believe that graft preservation is not an option as outcomes are even worse than for other agents [8]. In a study that included 9 cases of Pseudomonas aeruginosa infections, successful graft preservation was accomplished in only $44 \%$ (4 of 9) of cases, compared to $70 \%$ and $92 \%$ of cases when Gram positive bacteria or other Gram-negative bacteria were cultured, respectively [4]. 
However, in-hospital mortality in patients that undergo graft excision is significant, reported to be as high as $48 \%$ [9], and in some cases technically very difficult. In our patient, this was an obstacle for a quicker decision for open surgery. Our patient survived complex surgery and according to the literature survival rate ranges from $63-73 \%$ at 3 years of follow-up $[10,11]$.

\section{Conclusions}

Our case highlights the importance of maintaining a high suspicion of endovascular infection if a patient with a vascular graft has persistent bacteremia even if the imaging tests do not contribute to its confirmation. In our patient, Angio-CT and LeukoScan ${ }^{\circledR}$ had limited value and it was the PET scan which was decisive. Persistence and clinical judgment are essential when pursuing endovascular infection diagnosis.

On the other hand, the decision to remove an aortic graft, a surgery that implies a high mortality, may be difficult but may be the only curative strategy. Although the isolation of a microorganism allowed direct antibiotic therapy in this case, bacteremia persisted while graft was in place.

Due to the challenges that these infections pose, the management of these patients should be carried out in multidisciplinary teams that include vascular surgeons and infectious disease specialists.

Author Contributions: Conceptualization, R.F., F.C., A.C.C. and M.T.; investigation: R.F., R.F., F.C. and A.C.C.; writing-original draft preparation: R.F., R.F., F.C. and A.C.C.; writing-review and editing: R.F., R.F., F.C., A.C.C., M.T., J.T. and A.S. All authors have read and agreed to the published version of the manuscript.

Funding: This research received no external funding.

Conflicts of Interest: The authors declare no conflict of interest.

\section{References}

1. Treska, V.; Certik, B.; Molacek, J. Management of aortic graft infections-The present strategy and future perspectives. Bratisl Lek Listy. 2016, 117, 125-132. [CrossRef] [PubMed]

2. Vogel, T.R.; Symons, R.; Flum, D.R. The incidence and factors associated with graft infection after aortic aneurysm repair. J. Vasc. Surg. 2008, 47, 264-269. [CrossRef] [PubMed]

3. Setacci, C.; Chisci, E.; Setacci, F.; Ercolini, L.; de Donato, G.; Troisi, N.; Galzerano, G.; Michelagnoli, S. How to Diagnose and Manage Infected Endografts after Endovascular Aneurysm Repair. Aorta J. 2014, 2, 255-264. [CrossRef] [PubMed]

4. Calligaro, K.D.; Veith, F.J.; Schwartz, M.L.; Savarese, R.P.; DeLaurentis, D.A. Are gram-negative bacteria a contraindication to selective preservation of infected prosthetic arterial grafts? J. Vasc. Surg. 1992, 16, 337-346. [CrossRef]

5. Santini, C.; Baiocchi, P.; Venditti, M.; Brandimarte, C.; Tarasi, A.; Rizzo, L.; Speziale, F.; Fiorani, P.; Serra, P. Aorto-femoral graft infections: A clinical and microbiological analysis. J. Infect. 1993, 27, 17-26. [CrossRef]

6. Spacek, M.; Belohlavek, O.; Votrubova, J; Sebesta, P.; Stadler, P. Diagnostics of "non-acute" vascular prosthesis infection using 18F-FDG PET/CT: Our experience with 96 prostheses. Eur. J. Nucl. Med. Mol. Imaging 2009, 36, 850-858. [CrossRef] [PubMed]

7. Cernohorsky, P.; Reijnen, M.M.P.J.; Tielliu, I.F.J; van Sterkenburg, S.M.M.; van den Dungen, J.-J.A.M.; Zeebregts, C.J. The relevance of aortic endograft prosthetic infection. J. Vasc. Surg. 2011, 54, 327-333. [CrossRef] [PubMed]

8. Terpling, S.; Schade Larsen, C.; Schønheyder, H.C. Long-term home-based parenteral antibiotic treatment of a prosthetic vascular graft infection caused by Pseudomonas aeruginosa. Scand. J. Infect. Dis. 2006, 35, 388-392. [CrossRef] [PubMed]

9. Garot, M.; Delannoy, P.; Meybeck, A.; Sarraz-Bournet, B.; Elia, P.; Escrivan, T.; Devos, P.; Leroy, O. Intra-abdominal aortic graft infection: Prognostic factors associated with in-hospital mortality. BMC Infect. Dis. 2014, 14, 1-7. [CrossRef] [PubMed]

10. Smeds, M.R.; Duncan, A.A.; Harlander-Locke, M.P.; Lawrence, P.F.; Lyden, S.; Fatima, J.; Eskandari, M.K.; Steenberge, S.P.; Tomita, T.M.; Morasch, M.; et al. Treatment and outcomes of aortic endograft infection. J. Vasc. Surg. 2014, 63, 332-340. [CrossRef] [PubMed] 
11. Seeger, J.M.; Pretus, H.A.; Welborn, M.B.; Ozaki, C.K.; Flynn, T.C.; Huber, T.S. Long-term outcome after treatment of aortic graft infection with staged extra- anatomic bypass grafting and aortic graft removal. J. Vasc. Surg. 2000, 286, 451-461. [CrossRef] [PubMed]

Publisher's Note: MDPI stays neutral with regard to jurisdictional claims in published maps and institutional affiliations.

(C) 2020 by the authors. Licensee MDPI, Basel, Switzerland. This article is an open access article distributed under the terms and conditions of the Creative Commons Attribution (CC BY) license (http://creativecommons.org/licenses/by/4.0/). 